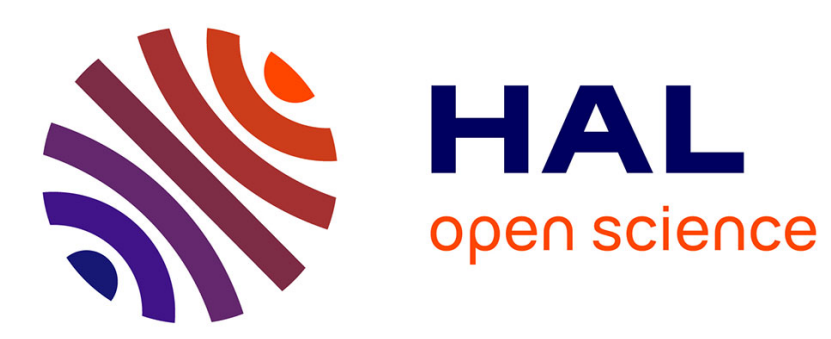

\title{
Contribution of the fluorescence to conversion electron yield X-ray absorption fine-structure measurements
}

Olivier Proux, Jean Mimault, Thierry Girardeau

\section{To cite this version:}

Olivier Proux, Jean Mimault, Thierry Girardeau. Contribution of the fluorescence to conversion electron yield X-ray absorption fine-structure measurements. Philosophical Magazine a, 2001, 81 (9), pp.2199-2215. 10.1080/01418610108217143 . hal-02176204

\section{HAL Id: hal-02176204 \\ https://hal.science/hal-02176204}

Submitted on 7 Jul 2019

HAL is a multi-disciplinary open access archive for the deposit and dissemination of scientific research documents, whether they are published or not. The documents may come from teaching and research institutions in France or abroad, or from public or private research centers.
L'archive ouverte pluridisciplinaire HAL, est destinée au dépôt et à la diffusion de documents scientifiques de niveau recherche, publiés ou non, émanant des établissements d'enseignement et de recherche français ou étrangers, des laboratoires publics ou privés. 


\title{
CONTRIBUTION OF THE FLUORESCENCE IN THE CONVERSION ELECTRON YIELD XAFS MEASUREMENTS
}

\author{
O. ProuX ${ }^{1}$, J. MimaulT ${ }^{2}$ and T. GIRARDEAU ${ }^{2}$ \\ 1 Laboratoire de Cristallographie, CNRS \\ 25 Avenue des Martyrs - BP 166 - 38042 Grenoble cedex 9 \\ 2 Laboratoire de Métallurgie Physique, U.M.R. CNRS 6630 \\ SP2MI, Bd Marie et Pierre Curie, Téléport 2, B.P. 179, F-86960 Futuroscope Cedex
}

\begin{abstract}
Influence of an extra electron yield induced by the fluorescence process has been experimentally shown and analytically described. Analyse of the Conversion Electron Yield signal induced by pure bulk silver (Ag K-edge) and pure bulk nickel or copper recovered by a thin iron layer ( $\mathrm{Ni}$ and $\mathrm{Cu} \mathrm{K}$-edges) has been performed. This fluorescence-electron yield leads to enhance the edge-height to modify the shape of the XANES and to decrease the EXAFS amplitude. Extrapolation of the model concerning unrecovered bulk samples was carried out in order to explain the EXAFS amplitude reduction often observed in CEY measurements referring to that obtained in the transmission mode. Such reduction $\Delta \chi / \chi$ increases with the atomic number $\mathrm{Z}$ of the studied element. $\Delta \chi / \chi$ can be considered as negligible for low-Z element ( $\mathrm{Ni}$ and $\mathrm{Cu}$ ). It becomes important for high-Z element. K-dependence of the amplitude reduction is rather limited and such reduction can be simply explained by a proportional factor. In order to correct this unwanted effect, theoretical calculation process can be performed or sample structure can be especially designed to minimise it. Thin films deposited on substrate composed of low-Z element do not generate significantly such extra electron yield.
\end{abstract}

https://doi.org/10.1080/01418610108217143

\footnotetext{
$\S$ tel. : 33 (0)4 76882547 - Email : proux@esrf.fr
} 


\section{$\S$ 1. INTRODUCTION}

Measurements of Extended X-ray Absorption Fine Structure (EXAFS) obtained via the total electron yield detection are now commonly used to carry out information about the local structure of specimens which cannot be probed by transmission or fluorescence mode. The resulting Conversion Electron Yield signal (CEY) is essentially characteristic of atoms confined at or near the probed surface. ${ }^{1}$ This specificity is well-suited to deepen the structure obtained in thin layers deposited on absorbing substrates or to follow structural modifications induced by various surface treatments such as ion neutron or electron irradiations - which are depth-limited. Experiments have to be planned taking this CEY depthdependence into account. This parameter is now relatively well-known and several models can be used to determine its behaviour versus the chosen edge and its atomic nature as well as the composition and structure of probed samples. ${ }^{2,3,4}$

However it remains numerous questions about an amplitude reduction frequently observed on EXAFS spectra deduced from CEY when it is compared to a reference one obtained on a transmission device ${ }^{5,6}$. The decrease can be attributed to the detection technique itself which collects all kinds of electrons including those due to the self-absorption of fluorescence photons. The latter are specific to the investigated edge absorption and are emitted during the decay process. ${ }^{7}$ Apart from some very particular configurations - as for instance very low atomic concentration - this signal fraction shows its main failing which consists in a non-linear absorption behaviour. EXAFS oscillations can then be modified differently versus the probed edge and their subsequent use leads to an erroneous structure modelisation. Edgeheights specific of the different atomic species which constitutes a sample have to be considered with care before any comparison and use. This last point has already been underlined in previous studies ${ }^{2}$ about the alloy composition so obtained.

We have made a brief recall on the dependence of the sampling depth profiles versus the spectra energy. The main purpose of this paper though is firstly to give experimental evidence of this unwanted fluorescence yield secondly to precise its extent on the height of the experimented edge and finally to give an order of its influence at once on the amplitudes of the EXAFS signal and XANES part. Experimental and theoretical investigations have been here restricted to the K-edge absorption. First of all we outlined several experimental evidences of this additive electron yield obtained for pure metallic samples - some of them being recovered by a thin deposited film which nature and thickness were chosen to emphasise its part in the total yield. Second of all we splitted up the whole additive electron emission process and adapted the formalism developed by Schrœder et al. ${ }^{5}$ to derive an analytical expression. This theoretical results is compared to the observed differences between signals issued from CEY and transmission modes.

\footnotetext{
${ }^{1}$ Kordesch, M.E. and Hoffman, R.W., 1984, Phys. Rev. B, 29, 491

2 Erbil, A., Cargill III, G.S., Frahm, R. and Bœhme, R.F., 1988, Phys. Rev. B, 37, 2450

${ }^{3}$ Girardeau, T., Mimault, J., Jaouen, M., Chartier, P. and Tourillon, G., 1992, Phys. Rev. B, 46, 7144

${ }^{4}$ Schrœder, S.L.M., 1996, Solid State Commun., 98, 405

5 Schrœder, S.L.M., 1996, PhD Thesis, University of Cambridge

6 Schrœder, S.L.M., Moggridge, G.D., Lambert, R.M. and Rayment, T., 1997, J. Phys. IV, 7, 91 | Schroder, S.L.M., Moggridge, G.D., Lambert,

R.M. and Rayment, T., 1998, Advances in Spectroscopy, Vol. 26, edited by Clark, R.J.H. and Hester, R.E., chapter 1, pp 1-70
} 


\section{§ 2. ANALYTICAL BEHAVIOUR IN CEY MODE}

\subsection{Sampling depth}

Pre-edge or edge-height behaviour versus the deposited thickness has often been probed in order to define a sampling depth. In a previous work ${ }^{2}$ experimental evidences were found of a closely relation between the probed depth range and the energy $\mathrm{E}_{\mathrm{p}}$ of the "primary" electrons. These electrons result from the atomic excitation or desexcitation process and are at the basis of the measured electron yield. The term "primary" means a photoelectron (K or L) or an Auger electron (KLL or LMM) which either exits directly out of the surface or generates secondary electrons in cascades of inelastic collisions. Pre-edge and K-edge yields seem quasi exclusively related to the L photoelectron and KLL Auger electron energies respectively. It was experimentally shown that excited atoms located at a distance $\mathrm{z}$ away from the irradiated surface approximately provide an escaping current probability $\mathrm{P}_{1}(\mathrm{z})$ which is exponentially decreasing versus $z .{ }^{8}$ A sampling depth $D_{p}$ were then naturally defined to fit such an experimental behaviour: $\exp \left(-\mathrm{z} / \mathrm{D}_{\mathrm{p}}\right)\left(\mathrm{D}_{\mathrm{p}}=\mathrm{D}_{\mathrm{Ph}}\right.$ for photoelectrons, $\mathrm{D}_{\mathrm{Au}}$ for Auger electrons).

Referring to the previously mentioned experimental results and versus the thickness $\delta$ of the probed layer the total electron yield behaviour can be analytically plotted by the expression :

$$
\left.\mathrm{S}_{1}(\delta)=\int_{0}^{\delta} \mathrm{P}_{1}(\mathrm{z}) \mathrm{dz}=\mathrm{S}_{\infty}\left[1-\exp -\delta / \mathrm{D}_{\mathrm{P}}\right)\right]
$$

$D_{p}$ values always are much shorter than the $1 / \mu\left(E_{K}\right)$ absorbing $X$-ray length where $E_{K}$ is the $K$-edge energy and $\mu\left(E_{K}\right)$ the absorption cross-section at this energy. For layers where $\delta$ is of $D_{p}$ order the incoming X-ray flow is then considered to be rather constant through the whole specimen and the fluorescence phenomena intensity already rather negligible. $S_{\infty}$ means the electron yield due to a large (semi-infinite) sample and free of any fluorescence contribution.

Theoretical models were also recently developed to estimate an escaping probability function where $\mathrm{E}_{\mathrm{p}}$ appears through a distance parameter. Numerical computations were then done ${ }^{4}$ using a Monte-Carlo simulation algorithm and taking into account elastic inelastic scattering and energy losses to evaluate an escaping probability function $\mathrm{P}_{2}(\mathrm{z})$. They result in a set of calculated points which were well-plotted analytically by the following function:

$$
\mathrm{P}_{2}(\mathrm{z})=0.76 \times\left[1-2\left(\mathrm{z} / \mathrm{R}_{\mathrm{B}}\right)\right] \times \exp \left[-2.7\left(\mathrm{z} / \mathrm{R}_{\mathrm{B}}\right)\right]
$$

The Bethe range $\left(\mathrm{R}_{\mathrm{B}}\right)$ of the primary electrons is the total path length covered before all its kinetic energy is lost. ${ }^{9}$ Starting with this analytic function a theoretical profile $S_{2}(\delta)$ of the total electron yield is immediately obtained as in equation 1 . The result is generally more adapted to the experiment than the

\footnotetext{
7 Tröger, L., Arvanitis, D., Baberschke, K., Michaelis, H., Grimm, U. and Zschech, E., 1992, Phys Rev B, 46, 3283

8 Jones, R.G. and Woodruff, 1982, Surf. Sci., 114, 38

9 Joy, D.C. and Luo, S., 1989, Scanning, 11, 176
} 
simplest and approximate $\mathrm{S}_{1}(\delta)$. For instance concerning the largest thickness $\delta, \mathrm{S}_{2}(\delta)$ becomes more rapidly constant. This saturation is generally effective for a distance $\mathrm{D}_{\mathrm{S}} \approx 2 \mathrm{D}_{\mathrm{p}}$.

Numerous experimental values of $D_{p}$ can be found in literature for measurements done under $\mathrm{He}$ atmospheric pressure ${ }^{2,10,11,12}$. They were determined by adjustment of the experimental edge-height behaviour. Results obviously show that the product $\rho \times D_{p}$ is related to $E_{p}$ by a power law :

$$
\rho \times D_{P}=C \times E_{p}^{\alpha}
$$

$\rho$ being the specific density of the probed material. Fit gives $\alpha \approx 2.2$ and $C \approx 7.3$ in the $[4,10 \mathrm{keV}]$ energy range $\mathrm{D}_{\mathrm{p}}$ being in $\mathrm{nm}$ and $\mathrm{E}_{\mathrm{p}}$ in $\mathrm{keV}$.

\subsection{Electron yield magnitudes}

Considering a particular primary electron type it seems very reasonable to assume that the corresponding conversion electron yield is proportional to both its kinetic energy and sampling depth. Such an assumption has to be easily tested at the K-edge of each atomic element measuring the pre-edge to Kedge ratio value typical of the same spectra. To perform such calculus, both pre-edge and K-edge values are taken at the same energy and are characteristic of the same specimen. Much difficulty appears when the test concerns different atomic elements with different probed structures and energy ranges. Other parameters such as the incident X-ray measurement mode and surface density would be also considered ${ }^{2}$. Following this assumption and for sufficiently deep sample - $\exp \left(-\delta / \mathrm{D}_{\mathrm{p}}\right) \approx 0$ - the expression of the electron yield magnitude relative to the $\mathrm{E}_{\mathrm{p}}$ energy can be written as :

$$
S_{\infty, P}=I_{0} \times(1-\omega) \times \frac{\mu_{K}\left(E_{K}\right) \times E_{P} \times D_{P}}{\cos \beta+\mu\left(E_{K}\right) \times D_{P}}
$$

$\beta$ being the incidence of the X-ray beam on the sample surface, the (1- $\omega)$ factor the contribution of Auger electrons ( $\omega$ being the radiative decay probability), $\mu\left(E_{K}\right)$ and $\mu_{K}\left(E_{K}\right)$ the total and K-edge absorption cross-sections for the $\mathrm{E}_{\mathrm{K}}$ energy respectively.

\section{§ 3. FLUORESCENCE ELECTRON YIELD}

\subsection{Composition of pre-edge and K-edge electron yields}

Considering pure material and K-edge study, the fluorescent X-ray flow - which is incoming toward the front surface of the sample and consequently irradiates atoms near the surface - becomes only efficient when the energy of the incident $\mathrm{X}$ ray beam reaches or exceeds $\mathrm{E}_{\mathrm{K}}$ i.e. the probed $\mathrm{K}$ threshold energy. As

\footnotetext{
${ }^{10}$ Chartier, P., Riviere, J.P., Mimault, J. and Girardeau, T., 1995, Nucl. Instrum. Methods B, 95, 327

11 Bouldin, C.E., Forman, R.A. and Bell, M.I., 1987, Phys. Rev. B, 35, 1429
} 
a matter of fact the pre-edge electron yield is essentially built up from L photoelectrons. The subsequent atomic decay which follows an L absorption event involves energetically weak LMM Auger electrons which signal weight can be considered as relatively negligible. The complementary radiative decay fraction never goes beyond a few per cent for the present experimented elements. Moreover it induces very soft X-rays which are highly absorbed. So that even for thicker materials it can never induce an important X-ray fluorescent flow at its front surface. The $S_{L}$ pre-edge electron yield will then be practically considered as being always free of any fluorescent part.

Conversely just above the K-edge energy of K-photoelectrons is very low in comparison of the Auger KLL electrons issued from the subsequent decay. Besides, $\mathrm{K}_{\alpha}$ and $\mathrm{K}_{\beta}$ fluorescence X-rays must greatly modify the Auger electronic yield. Such an assertion is qualitatively supported by several elements. Firstly the decay radiative part is generally important apart from light atomic elements. Secondly, the $\mathrm{K}_{\alpha}$ and $\mathrm{K}_{\beta}$ photons absorption cœfficients become substantially lower relatively to the incident X-ray one. A cumulative increasing flow is consequently crossing towards the front surface. Their own atomic absorption gives rise to $\mathrm{L}$ photoelectrons which energy remains of the same order than the primary Auger ones. Therefore, an extra electron flow exits out of the surface. Its relative intensity is related to both thickness and atomic composition.

\subsection{Selection of appropriate experiments}

\subsubsection{Relative effect on K-edge yields}

The simpler way to probe quantitatively the "self absorption" weight in the collected electron yield is to compare the CEY pre-edge and K-edge values obtained on bulk samples and behaviours displayed by deposited layers versus the deposited thickness of thin films.

A bulk sample will allow the advisability of a complete attenuation of the X-ray incident beam. That makes further computations easier to evaluate the fluorescence electron yield ratio. This procedure becomes very relevant when the radiative decay probability $\omega$ is large enough - that is effective for high atomic number elements. Absorption CEY spectra were then performed on silver material $(\omega=0.83)$ around the K-edge $\left(\mathrm{E}_{\mathrm{K}}=25.514 \mathrm{KeV}\right)$.

The depth of deposited Ag layers was running from 125 to $1000 \mathrm{~nm}$. Such thickness range is large enough to obtain the saturation step of the CEY signal induced by Auger yield but also sufficiently far from the X-ray attenuation length - around 114 and $17 \mu \mathrm{m}$ before and after the Ag K-edge respectively. ${ }^{13}$ Therefore this sample set is considered as free of any $\mathrm{K}_{\alpha}(\mathrm{Ag})$ and $\mathrm{K}_{\beta}(\mathrm{Ag})$ fluorescence yield. Around $25 \mathrm{keV}$ the substrate (polished quartz) displays very low absorption cœfficients and its own electron yields counted in the pre-edge one is greatly weakened by the deposited silver layer. Moreover for incident photons at 25 $\mathrm{keV}$ energies of the $\mathrm{Ag} \mathrm{L}$ photoelectrons and $\mathrm{Si} \mathrm{K}$ ones are of the same order of magnitude.

\footnotetext{
12 Yanase, E., Dake, Y., Sakiyama, M., Tohkai, M., Watanabe, I., Harada, M. and Takahashi, M., 1996, Oyo Buturi, 65, 1267

13 McMaster, W.H., Del Grande, N.K., Mallet, J.H. and Hubell, J.H., 1969, Lawrence Livermore Laboratory Report, Sec. II, Rev. 1
} 


\subsubsection{Absolute effect on EXAFS or XANES spectrum}

Compared to bulk material, layers deposited by sputtering process are generally constituted of very small crystallites which can induce a size-effect reduction on the amplitude of the correspondent EXAFS signal. Measurements have then to be free of such an artefact in order to probe the signal deformation exclusively due to the fluorescent $K_{\alpha}$ and $K_{\beta}$ electron yield. Moreover copper or nickel materials are more well-suited than the silver one to obtain a good signal-to-noise ratio on EXAFS spectrum performed on the used beamline. A second set of samples was then prepared to especially give prominence to the fluorescence effect at $\mathrm{Ni}$ and $\mathrm{Cu} \mathrm{K}$-edges. Several pure bulk $\mathrm{Ni}$ (or $\mathrm{Cu}$ ) samples were cut in the same piece of metal. Some of them being were recovered by a thin deposited iron film which thickness and nature were chosen in the following way.

Thickness is adjusted in order to try to annihilate the substrate $\mathrm{Ni}(\mathrm{Cu}) \mathrm{CEY}$ without any noticed modification though on the fluorescent $\mathrm{Ni}(\mathrm{Cu}) \mathrm{K}_{\alpha}$ and $\mathrm{K}_{\beta} \mathrm{X}$-ray flow crossing the surface of the sample. In $\mathrm{Ni}(\mathrm{Cu})$ materials, $\mathrm{D}_{\mathrm{S}}$ is expected to be largely lower than $200 \mathrm{~nm}$ for Auger "primary" electrons and $\mathrm{X}$-ray attenuation depth is about $4 \mu \mathrm{m}$ just above the K-edges (McMaster et al. 1969). A $200 \mathrm{~nm} \mathrm{Fe}$ sublayer is a good compromise between the two previous requirements. To appreciate any remaining substrate $\mathrm{Ni}(\mathrm{Cu})$ electron yield, the same iron deposition was done on a $200 \mathrm{~nm}$ thick $\mathrm{Ni}(\mathrm{Cu})$ underlayer. Moreover, this sublayer is sufficiently deep to give a quasi complete electron yield signal, at its own K-edge.

Nature of the sublayer is chosen in order to emphasise the resulting electron yield of the $\mathrm{Ni}(\mathrm{Cu}) \mathrm{K}_{\alpha}$ and $\mathrm{K}_{\beta}$ X-ray absorption effect. Unlike into $\mathrm{Ni}(\mathrm{Cu})$ material, $\mathrm{K}_{\alpha}$ and $\mathrm{K}_{\beta} \mathrm{Ni}(\mathrm{Cu})$ X-rays absorption in $\mathrm{Fe}$ material derives mainly of a $\mathrm{K}$ process which is typical of a high absorption cross-section.

Bulk materials are known to have large crystalline grains which minimise the previously mentioned sizeeffect amplitude reduction. Then, bulk recovered samples are expected to measure a signal quasi proportional to the only fluorescent electron yield. Specific data of bare bulk samples will be used for further theoretical tests. $\mathrm{Cu}$ and Ni $5 \mu \mathrm{m}$ thick foils have also been probed in a transmission mode to give XANES or EXAFS signal references.

\section{§ 4. EXPERIMENT}

\subsection{Experimental details}

Layer deposition was performed by using an argon-ion beam sputtering technique on a pure $\mathrm{Fe}, \mathrm{Cu}$, $\mathrm{Ni}$ or $\mathrm{Ag}$ target. The beam energy was fixed to $1.2 \mathrm{keV}$ for a ionic current of $80 \mathrm{~mA}$. Base pressure in the chamber was $10^{-7}$ torr and did not exceed $10^{-4}$ torr during the deposition step. Samples were all $12 \times 18$ $\mathrm{mm}^{2}$ surface sized. Bulk substrates were polished till a mirror finish before their use.

Absorption spectroscopy spectra were performed at LURE (Orsay, France) using synchrotron radiation from the DCI storage ring operating with an energy of $1.85 \mathrm{GeV}$. Data was recorded on the D42 station 
using a (331) Si channel-cut monochromator. For the Ag sample set - which requires several different incident angles - CEY measurements were carried out by using a room temperature detector. ${ }^{14}$ Incidences can be fixed with an error bare of $2^{\circ}$. The other samples, which were probed for the details of their spectra, were introduced, at a constant incidence, into a device designed to be cooled at liquid nitrogen temperature. ${ }^{15}$ An improved signal-to-noise ratio is then obtained on an enlarged energy range of the EXAFS spectra. All the data points were collected during 2s, under an atmospheric helium pressure, with an energy step of $0.5 \mathrm{eV}$ or $2 \mathrm{eV}$ in their XANES or EXAFS range, respectively. Each set of samples was probed with the same beamline and detection adjustments and all the samples were strictly positioned at the same place on the sample holder.

\subsection{Results}

\subsubsection{Silver spectra}

As a first evidence that an extra electron yield is introduced in the $\mathrm{K}$ edge signal for bulk samples, we report on Fig. 1 an absolute absorption CEY spectra relative to the bulk and the $1000 \mathrm{~nm}$ layer silver for the same beam incidence of $60^{\circ}$ applied on both surfaces. One can get evidence that bulk materials exhibit an enhanced K-edge magnitude, until the pre-edge signal remains identical in both cases. As shown on this figure and to have further computations in mind to do, experimental magnitudes will be extracted just above the K-edge absorption threshold. Such procedure requires a very limited linear extrapolation of the pre-edge curve.

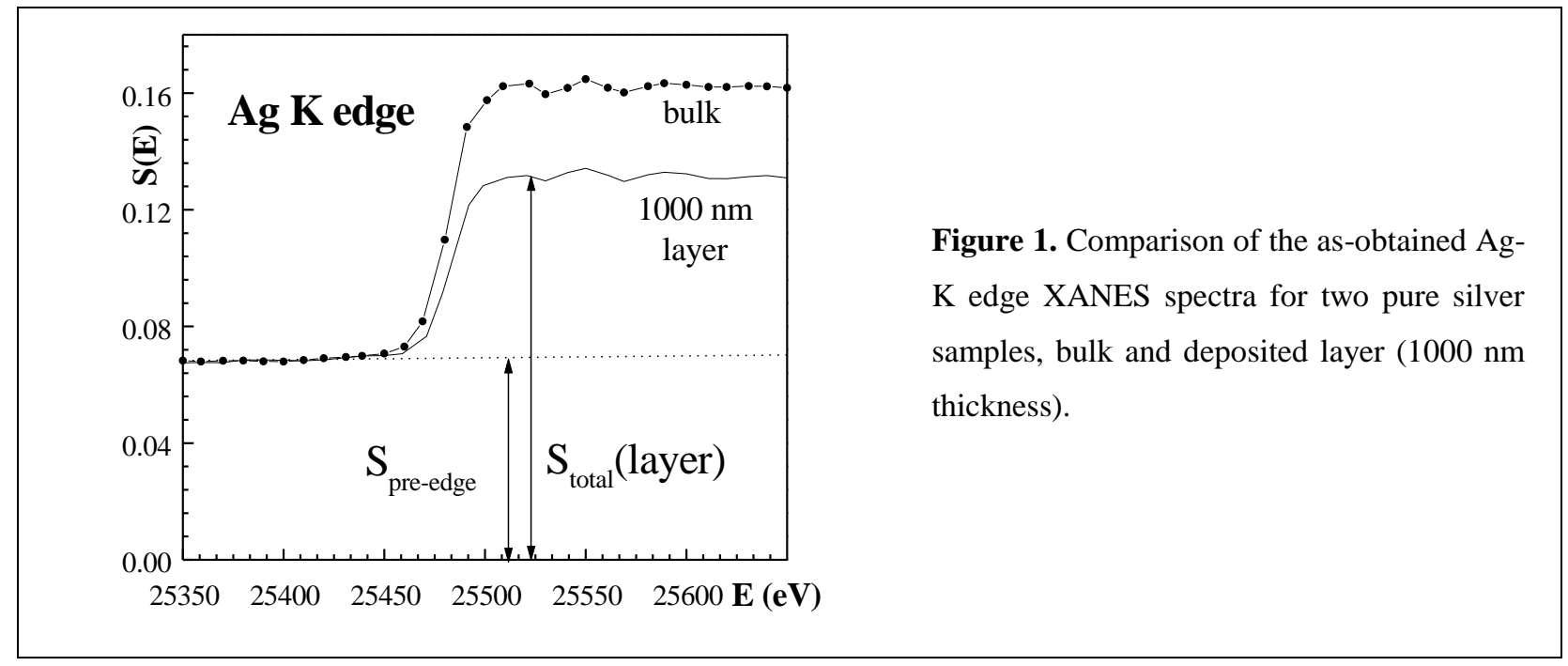

\footnotetext{
14 Tourillon, G., Dartyge, E., Fontaine, A., Lemonnier, M. and Bartol, F., 1987, Phys. Lett. A, 121, 251

15 Mimault, J., Faix, J.J., Girardeau, T., Jaouen, M. and Tourillon, G., 1994, Meas. Sci. Technol., 5, 482
} 


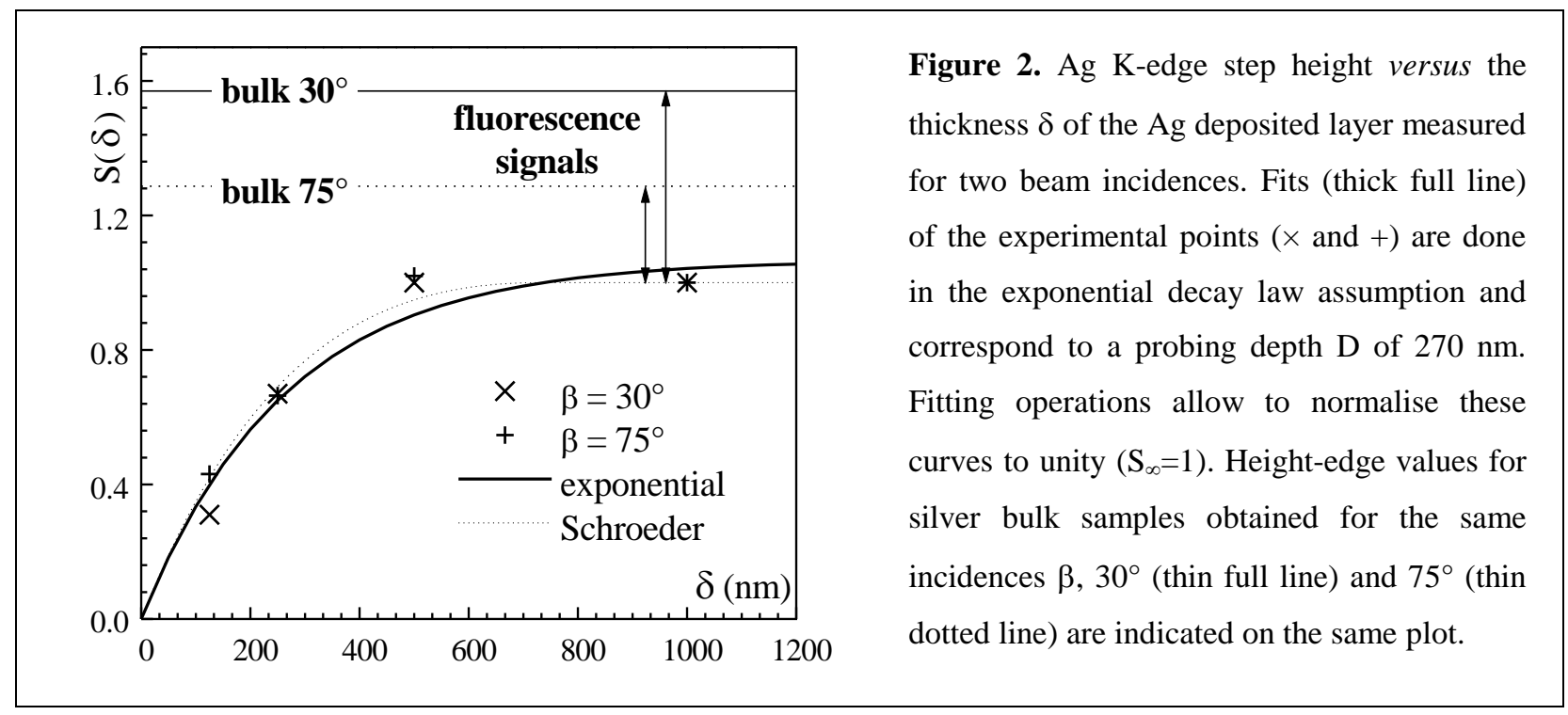

Relative behaviour of the K-edge magnitude versus the silver layer thickness is reported on Fig. 2 for two incident angles $\left(30^{\circ}\right.$ and $\left.75^{\circ}\right)$ in order to complete this first experimental view. The saturated signal is taken as a reference $\left(S_{\infty}=1\right)$. The variation is very similar for all the incident angles and the CEY saturation obviously appears around 500nm. Previously stated theoretical profiles of single-layer electron yield have been applied. The best fit being is obtained with $D_{A u}=270 \mathrm{~nm}$ for the simplest exponential expression $S_{1}(\delta)$ (eq. 1). The Monte-Carlo model agrees with a saturation process around $500 \mathrm{~nm}$. One can then consider that the fluorescence electron yield ratio, which is increasing with the incident angle, is given by the relative difference between the bulk and the $1000 \mathrm{~nm}$ layer results. It is an important amount since it varies relatively to the total signal approximately from $25 \%$ to $40 \%$ for $75^{\circ}$ to $30^{\circ}$ incidence conditions respectively (Tab. 1). Relative error bare on this percentages were estimated to be lower than $5 \%$.

\begin{tabular}{ccccccc}
\hline$\beta\left(^{\circ}\right)$ & 30 & 45 & 60 & 65 & 70 & 75 \\
\hline experiment & $0.41 \pm 0.01$ & $0.37 \pm 0.01$ & $0.31 \pm 0.01$ & $0.34 \pm 0.01$ & $0.31 \pm 0.02$ & $0.26 \pm 0.02$ \\
\hline model & 0.47 & 0.44 & 0.39 & 0.37 & 0.33 & 0.29 \\
\hline
\end{tabular}

Table 1. Comparison of the relative values of the fluorescence signal with respect to the total one, $S_{\text {fluo }} / S_{\text {total }}$, obtained for bulk silver by experiment and computation.

\subsubsection{Effects of a Fe sublayer}

We report on Fig. 3 absolute CEY spectra obtained on Fe/Ni systems, the 200nm Fe sublayer being deposited on a Ni bulk substrate (Fig. 3.a) or on a 200nm Ni thin film deposited itself on a quartz substrate (Fig. 3.b). Probed energy range covers both the iron and nickel K-edges. Ni K-edge magnitude appears much more limited in the $\mathrm{Ni} 200 \mathrm{~nm}$ layer case where the fluorescence effect must remain insignificant. 

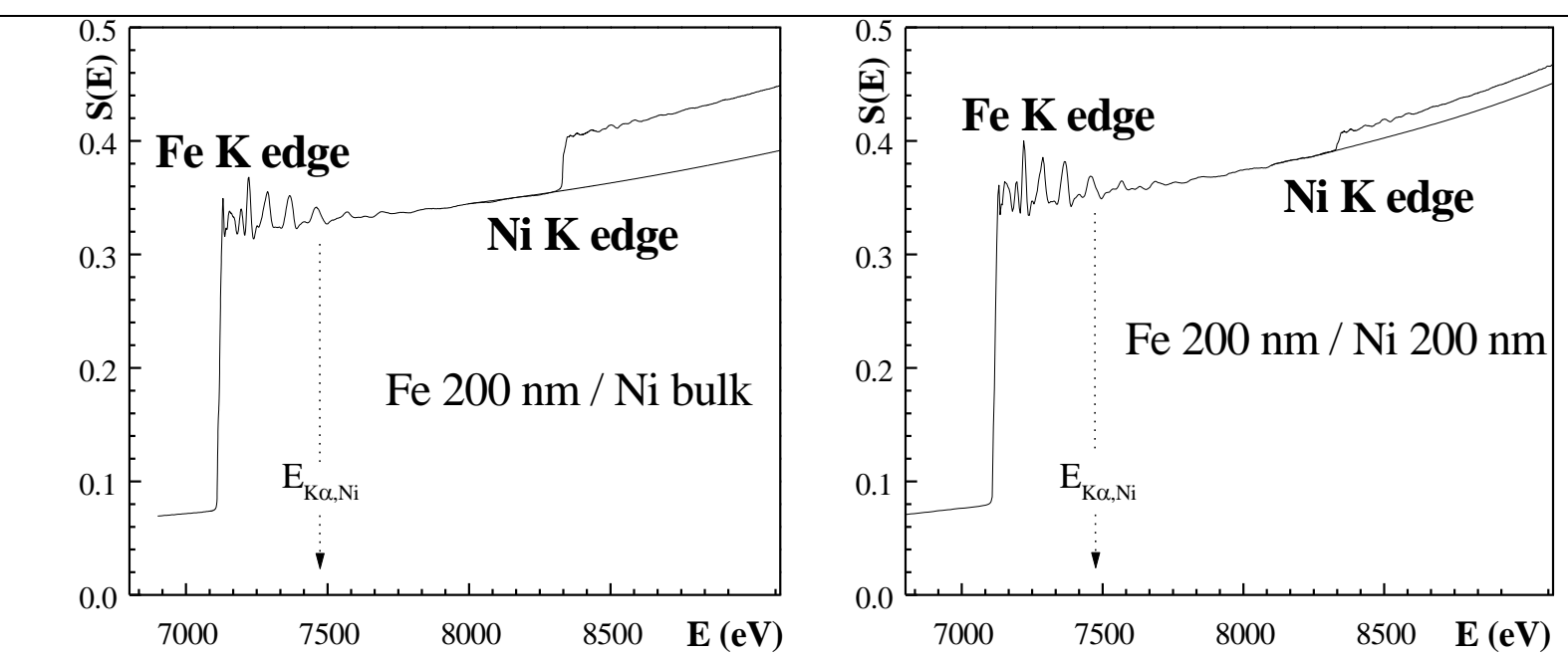

Figure 3. As-obtained Conversion Electron EXAFS spectra measured for the Fe/Ni system at Ni-K edge. Substrate of the $200 \mathrm{~nm}$ thick iron layer is a bulk nickel substrate (a) or a $200 \mathrm{~nm}$ thick nickel layer deposited on quartz (b).

Fe pre-edge and K-edge heights are very close to each other for both spectra. They can be considered as significant of quasi identical Fe deposited layers probed with the same X-ray beamline adjustments around this particular K-edge for both experiments. Nevertheless it is preferable to compare relative values, the mean slope of the whole spectrum being observed slightly different. The difference between the two Fe K-edge to pre-edge ratios is much lower than the error bare. In the same way Ni K-edge $(\mathrm{Cu})$ to pre-edge ratios have been reported on table 2 . Their difference is considered as weighting the pure fluorescence electron yield specific of the bulk material.

\begin{tabular}{ccc}
\hline $\mathrm{S}_{\mathrm{Fluo}}\left(\mathrm{E}_{\mathrm{K} \alpha}\right) / \mathrm{S}_{\mathrm{Fe}}\left(\mathrm{E}_{\mathrm{K} \alpha}\right)$ & $200 \mathrm{~nm} \mathrm{Fe} /$ bulk Ni & $200 \mathrm{~nm} \mathrm{Fe} / \mathrm{bulk} \mathrm{Cu}$ \\
\hline experiment : Fe(200nm) / bulk & 0.109 & 0.128 \\
\hline experiment : Fe(200nm) / layer(200nm) & 0.032 & 0.031 \\
\hline difference $: \mathrm{S}_{\text {fluo }} / \mathrm{S}_{\text {pre-edge }}$ & 0.077 & 0.097 \\
\hline model & 0.075 & 0.089 \\
\hline
\end{tabular}

Table 2. Experimental and computed results for the fluorescence yield signal versus the pre-edge one at the Ni and $\mathrm{Cu}$ K-edges for the two experimented systems.

Both normalised Ni K-edge spectra are superimposed on figure 4. On one hand the 400nm bilayer Fe-Ni case yields a spectra undoubtedly reliable to the well-known pure nickel one. On the other hand the Fe sublayer-Ni bulk case shows important modifications at once in its threshold shape and its oscillation amplitude with respect to the same standard one. 


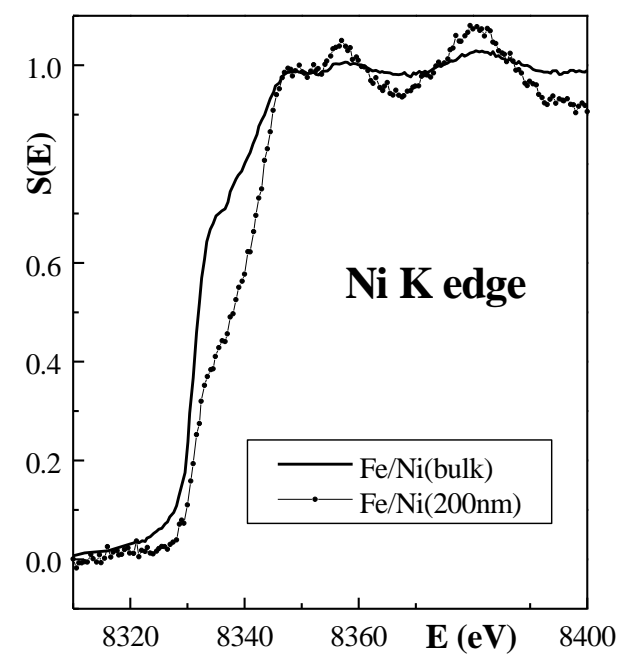

Figure 4. Comparison of the normalised XANES spectra obtained at the Ni-K edge for the $200 \mathrm{~nm}$ thick iron layer deposited on a bulk nickel substrate (thick full line) or on a $200 \mathrm{~nm}$ thick nickel layer deposited on quartz (thin full line with black circles).

\section{§ 5. MODELISATION OF THE FLUORESCENT ELECTRON YIELD}

Expressions of self-absorption effects, drawn up by Schrœder et al. ${ }^{5}$, have been developed in the particular case where the probed substrate $\left(\mathrm{Ni}\right.$ or $\mathrm{Cu}$ ) is covered by a thin layer (thickness $\delta_{\mathrm{Fe}}$ ) of iron. For much clarity, indexes are only stated for the Fe-Ni system. The X-ray absorption cross section $\mu$ is defined by length unit.

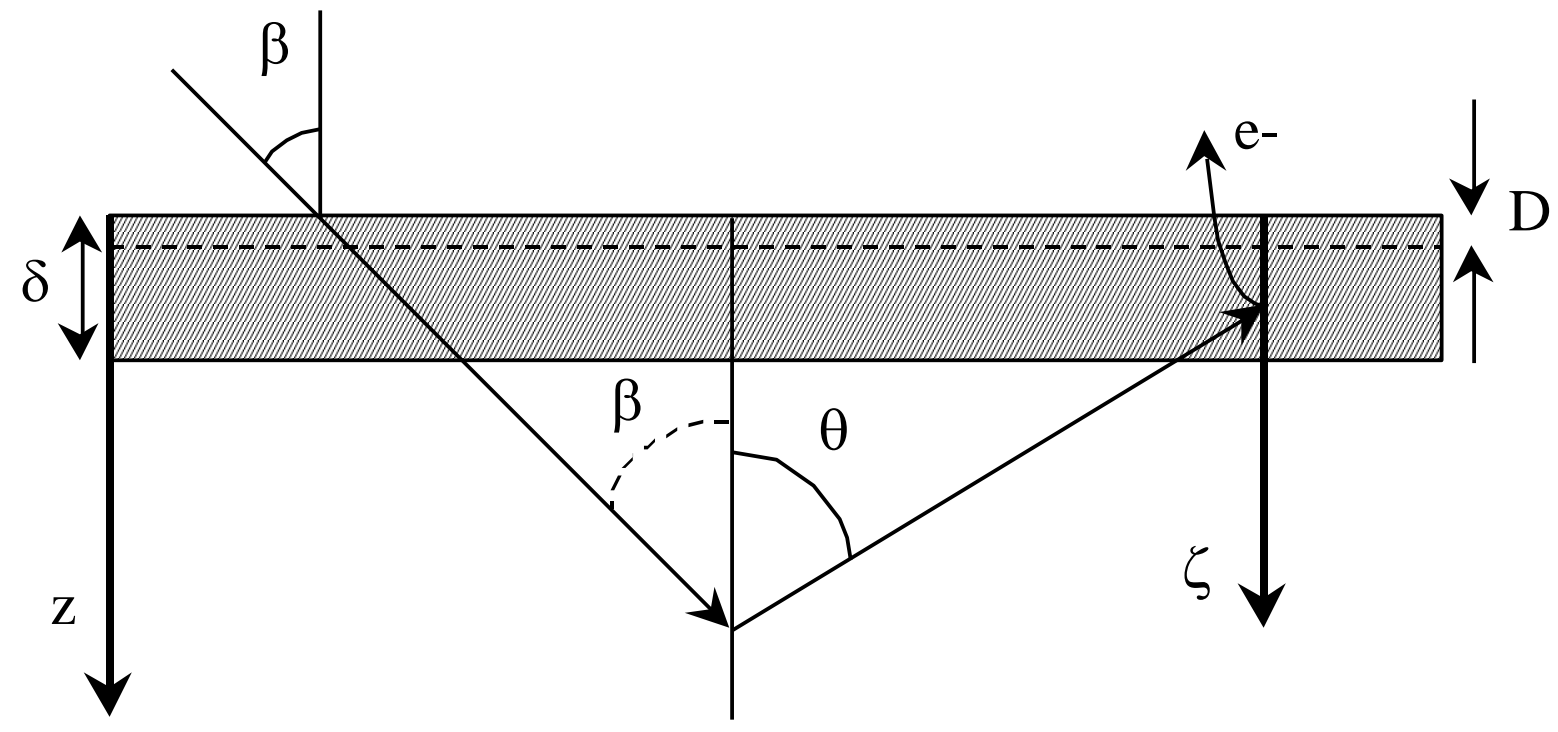

Figure 5. Geometrical description of the model used to calculate the self-absorption signal emitted by a bulk substrate (excited part of the sample) recovered by a layer (magnifying part for the "fluorescence" detection, annihilating one for the electron detection). All the different variables used for the analytical calculations are indicated i.e. the angular variables $\beta$ and $\theta$ and the depth ones $\mathrm{z}$ and $\zeta$.

The first step in the description of the whole process for such a sample configuration gives rise to a fluorescence $\mathrm{X}$-ray beam $\mathrm{dI}_{\mathrm{f}}(\mathrm{z})$. This elementary signal is created at a depth $\mathrm{z}$ by an infinitesimal slice $\mathrm{dz}$ 
of the nickel substrate. It can be spelt up in a set of sequences schematically sketched on figure 5. Each of them is generating a factor.

a) The incident $X$ ray beam (intensity $\mathrm{I}_{0}$ ), which is incoming towards the sample surface under an incident $\beta$ angle, has been attenuated by the Fe sublayer when it reaches the front surface of the Ni substrate: $\exp \left[-\mu_{\mathrm{Fe}}\left(\mathrm{E}_{\mathrm{i}}\right) \times \delta_{\mathrm{Fe}} / \cos \beta\right]$

b) In the same way, the intensity of the beam is attenuated by its path inside the nickel substrate (from the depth $\delta_{\mathrm{Fe}}$ to $\left.\mathrm{z}\right): \exp \left[-\mu_{\mathrm{Ni}}\left(\mathrm{E}_{\mathrm{i}}\right) \times\left(\mathrm{z}-\delta_{\mathrm{Fe}}\right) / \cos \beta\right]$

c) The K-level absorption probability factor of the $\mathrm{X}$ ray beam: $\mu_{\mathrm{K}, \mathrm{Ni}}\left(\mathrm{E}_{\mathrm{i}}\right) \times \mathrm{dz} / \cos \beta$

d) The radiative decay probability factor: $\omega_{\mathrm{Ni}}$

Multiplying all the previous factors results in the elementary fluorescent $\mathrm{X}$-ray $\mathrm{dI}_{\mathrm{f}}(\mathrm{z})$. The second step will be to clarify the fluorescence $X$-ray intensity $\mathrm{d}^{2} \mathrm{I}_{\mathrm{f}}(\mathrm{z})$ which irradiates the Fe slice $\mathrm{d} \zeta$, at a depth $\zeta$ near the front layer of the specimen.

Taking into account the relative weakness of the $\mathrm{K}_{\beta} / \mathrm{K}_{\alpha}$ emission ratio and to get further computations more easy, we will assume that the K-radiative decay is purely of $\mathrm{K}_{\alpha}$ type. The fluorescence phenomenon being also assumed to be spatially isotropic we will first consider X-rays which are crossing from the depth $\mathrm{z}$ around an incidence $\theta$ towards the surface.

e) Atoms of the Fe sublayer located at the depth $\zeta$ are irradiated by an attenuated X-ray beam : factors $\exp \left[-\mu_{\mathrm{Ni}}\left(\mathrm{E}_{\mathrm{K} \alpha}\right) \times\left(\mathrm{z}-\delta_{\mathrm{Fe}}\right) / \cos \theta\right]$ inside the $\mathrm{Ni}$ substrate and $\exp \left[-\mu_{\mathrm{Fe}}\left(\mathrm{E}_{\mathrm{K} \alpha}\right) \times\left(\delta_{\mathrm{Fe}}-\zeta\right) / \cos \theta\right]$ inside the Fe sublayer.

f) Gathering all the backcoming directions defined by an equivalent incidence $\theta$ and included in a width $\mathrm{d} \theta$ yields a new probability geometrical factor: $\sin \theta \mathrm{d} \theta / 2$.

Considering finally that the $\mathrm{K}_{\alpha, \mathrm{Ni}}$ (or $\mathrm{K}_{\beta, \mathrm{Ni}}$ ) X-ray absorption by $\mathrm{Fe}$ atoms is mainly of $\mathrm{K}$ type an expression of non radiative decay probability specific to the infinitesimal slice $(\zeta, \zeta+d \zeta)$ can be stated as $\left(1-\omega_{\mathrm{Fe}}\right) \times \mu_{\mathrm{Fe}}\left(\mathrm{E}_{\mathrm{K} \alpha}\right) \times \mathrm{d} \zeta / \cos \theta$. The resulting probability has to be multiplied 1$)$ by $\exp \left(-\zeta / \mathrm{D}_{\mathrm{Au}}(\mathrm{Fe})\right)$ in relation to the depth of the interaction and 2) by $\mathrm{E}_{\mathrm{Au}}(\mathrm{Fe})$ the Auger electron energy to obtain a final expression of the electron yield

Integration over $\mathrm{z}$ in the $[\mathrm{d}, \infty[$ range and $\zeta$ in the $[0, \mathrm{~d}]$ one are straightforward and we get:

$$
\mathrm{dS}(\theta)=\frac{\mu_{\mathrm{K}, \mathrm{Ni}}\left(\mathrm{E}_{\mathrm{i}}\right)}{\mu_{\mathrm{Ni}}\left(\mathrm{E}_{\mathrm{i}}\right) / \cos \beta+\mu_{\mathrm{Ni}}\left(\mathrm{E}_{\mathrm{K} \alpha}\right) / \cos \theta} \mathrm{F}(\theta) \mathrm{d} \theta
$$

As expected the final expression yields to a non linear behaviour part versus the $\mathrm{Ni}$ absorption crosssection $\mu_{\mathrm{K}, \mathrm{Ni}}\left(\mathrm{E}_{\mathrm{i}}\right.$ ) (appearing both at numerator and denominator) which depends of the orientation $\beta$ of the surface sample relatively to the incident X-ray beam. The fluorescence-induced signal has then a reduced oscillation amplitude with respect to the reference. This reduction is moreover all the more important since the $\beta$ angle is high - the $\mu_{\mathrm{Ni}}\left(\mathrm{E}_{\mathrm{i}}\right)$ denominator term being weighted by the $1 / \cos \beta$ factor.

Without any additive approximation the integration over $\theta$ from 0 to $\pi / 2$ can only be performed by the 
way of numerical computation. This is especially true if one want precisely to test the fluorescence effect on the EXAFS oscillations versus the incident energy $\mathrm{E}_{\mathrm{i}}$. Values reported on table 3 were used to perform such a computation for Fe on Ni or Cu bulk cases.

\begin{tabular}{ccccccc}
\hline element & $\omega(\%)$ & $\mathrm{E}_{\mathrm{K}}(\mathrm{keV})$ & $\mathrm{E}_{\mathrm{K} \alpha}(\mathrm{keV})$ & $\mu_{\mathrm{Fe}}\left(\mathrm{E}_{\mathrm{K} \alpha}\right)$ & $\mu_{\mathrm{K}, \mathrm{Fe}}\left(\mathrm{E}_{\mathrm{K} \alpha)}\right.$ & $\mu_{\mathrm{el} .}\left(\mathrm{E}_{\mathrm{K} \alpha}\right)$ \\
\hline $\mathrm{Ni}$ & 58.6 & $8.333 \mathrm{keV}$ & $7.477 \mathrm{keV}$ & $2881 \mathrm{~cm}-1$ & $2525 \mathrm{~cm}-1$ & $532 \mathrm{~cm}-1$ \\
\hline $\mathrm{Cu}$ & 55.5 & $8.979 \mathrm{keV}$ & $8.047 \mathrm{keV}$ & $2393 \mathrm{~cm}-1$ & $2103 \mathrm{~cm}-1$ & $459 \mathrm{~cm}-1$ \\
\hline
\end{tabular}

Table 3 : Numerical values using for computation. $\omega$ is the Auger decay probability, $E_{K}$ and $E_{K \alpha}$ the K-edge and fluorescence photon $\mathrm{K}_{\alpha}$ energies, $\mu_{\mathrm{Fe}}\left(\mathrm{E}_{\mathrm{K} \alpha}\right)$ and $\mu_{\mathrm{K}, \mathrm{Fe}}\left(\mathrm{E}_{\mathrm{K} \alpha)}\right.$ the total and K-edge iron absorption cœfficient for the particular energy $\mathrm{E}_{\mathrm{K} \alpha}$ and $\mu_{\mathrm{el} .}\left(\mathrm{E}_{\mathrm{K} \alpha}\right)$ the nickel or copper total absorption cœfficient for this same energy.

The computation process is somewhat different in the particular case of pure bulk sample. No sublayer has to be considered and the $\mathrm{K}_{\alpha}$ fluorescent X-ray beam essentially creates L photoelectrons (cf. §6.3). We will use $\mu_{\mathrm{Ag}}\left(\mathrm{E}_{\mathrm{K} \alpha}\right)=143 \mathrm{~cm}^{-1}$ for $\mathrm{E}_{\mathrm{K} \alpha}=22.162 \mathrm{KeV}$ in the particular case of bulk Ag sample studied at the Ag K-edge. Values of the absorption cross section were obtained from the Mac Master's table (McMaster et al. 1969) for each studied energies by using a Victoreen behaviour for extrapolation.

\section{§ 6. DISCUSSION}

\subsection{Relative intensities}

\subsubsection{Silver K-edge}

Relative intensity of the fluorescent electron yield can be extracted from spectra reported on figure 1 by subtracting the K-edge magnitude obtained for the deepest layers $\left(S_{\infty}\right)$ from the bulk one $\left(S_{\text {bulk }}\right)$. This quantity $\left[\mathrm{S}_{\text {bulk }}-\mathrm{S}_{\infty}\right] / \mathrm{S}_{\text {bulk }}-$ which is obviously representative of $\left[\mathrm{S}_{\text {fluo }} / \mathrm{S}_{\mathrm{K} \text {-edge }}\right]$ or $\left[\mathrm{S}_{\text {fluo }} /\left(\mathrm{S}_{\text {fluo }}+\mathrm{S}_{\text {Auger }}\right)\right]$ - were then measured for different $\beta$ angular incidences. Results are gathered on the first line of table 1 and can be compared to values computed via the model described in $\$ 5\left(2^{\text {nd }}\right.$ line $)$. Only the KLL Auger electrons (respectively the $\mathrm{L}$ photoelectrons) were considered for the $\mathrm{S}_{\text {Auger }}$ (respectively the $\mathrm{S}_{\text {fluo }}$ ) computation.

Computed and experimented values shows a similar behaviour versus the $\beta$ angular incidence in spite of some surely crude approximations (as $\mathrm{S} \propto \mathrm{E}_{\mathrm{P}}^{\alpha+1}$ ) which are certainly at the basis of the absolute differences. An experimental singularity revealed around $\beta=60^{\circ}$ and confirmed by several measures must also be noticed.

\subsubsection{Fe sublayer results}

Applied to the Fe layer / Ni bulk (or Fe layer / Cu bulk) sample, the previous described model results in a fluorescent electron yield $\mathrm{S}_{\text {fluo }}\left(\mathrm{E}_{\mathrm{K} \alpha}\right)$ at the $\mathrm{Ni}$ (or $\mathrm{Cu}$ ) K-edge. This yield can be directly compared to the $\mathrm{S}_{\mathrm{Fe}}\left(\mathrm{E}_{\mathrm{K} \alpha}\right)$ signal obtained when the Fe layer is irradiated by the incident $\mathrm{X}$-ray beam at the same $\mathrm{K}_{\alpha, \mathrm{Ni}}$ or 
$\mathrm{K}_{\alpha, \mathrm{Cu}}$ energy. A strictly identical absorption (and consecutive electronic output) process is involved in both cases in the Fe layer. The resulting $\mathrm{S}_{\mathrm{fluo}}\left(\mathrm{E}_{\mathrm{K} \alpha}\right) / \mathrm{S}_{\mathrm{Fe}}\left(\mathrm{E}_{\mathrm{K} \alpha}\right)$ ratio is only sensitive to the intensity and directional efficiency parameters which characterise the backward fluorescence X-ray beam relatively to the incident one. Computed results referred to the same incident $\mathrm{X}$-ray flow at $\mathrm{E}_{\mathrm{K} \alpha}$ and $\mathrm{E}_{\mathrm{K}}$ are reported on table 2 for both $\mathrm{K}$ edges. Extraction of experimental values from the data are less straightforward because of the efficiency of the incident X-ray detection which evolves in the $\left[\mathrm{E}_{\mathrm{K} \alpha}, \mathrm{E}_{\mathrm{K}}\right]$ range. Experimental Ni (and $\mathrm{Cu}$ ) $\mathrm{K}$-edge magnitudes must then be corrected to obtain the values which would be yielded if the incident beam X-ray detector was working at the $\mathrm{E}_{\mathrm{K} \alpha, \mathrm{Ni}}$ or $\mathrm{E}_{\mathrm{K} \alpha, \mathrm{Cu}}$ energy. We roughly assume a proportionality factor $\mathfrak{I} \approx \mu_{\text {air }}\left(\mathrm{E}_{\mathrm{K} \alpha}\right) \times \mathrm{E}_{\mathrm{K} \alpha}$. Magnitudes have then been divided by this factor $\mathfrak{I}$ which takes into account the variations of both the absorption cross section and the photoelectron output energy. The so-obtained results (table 2) show a good agreement with the computed ones.

\subsection{XANES and EXAFS signals}
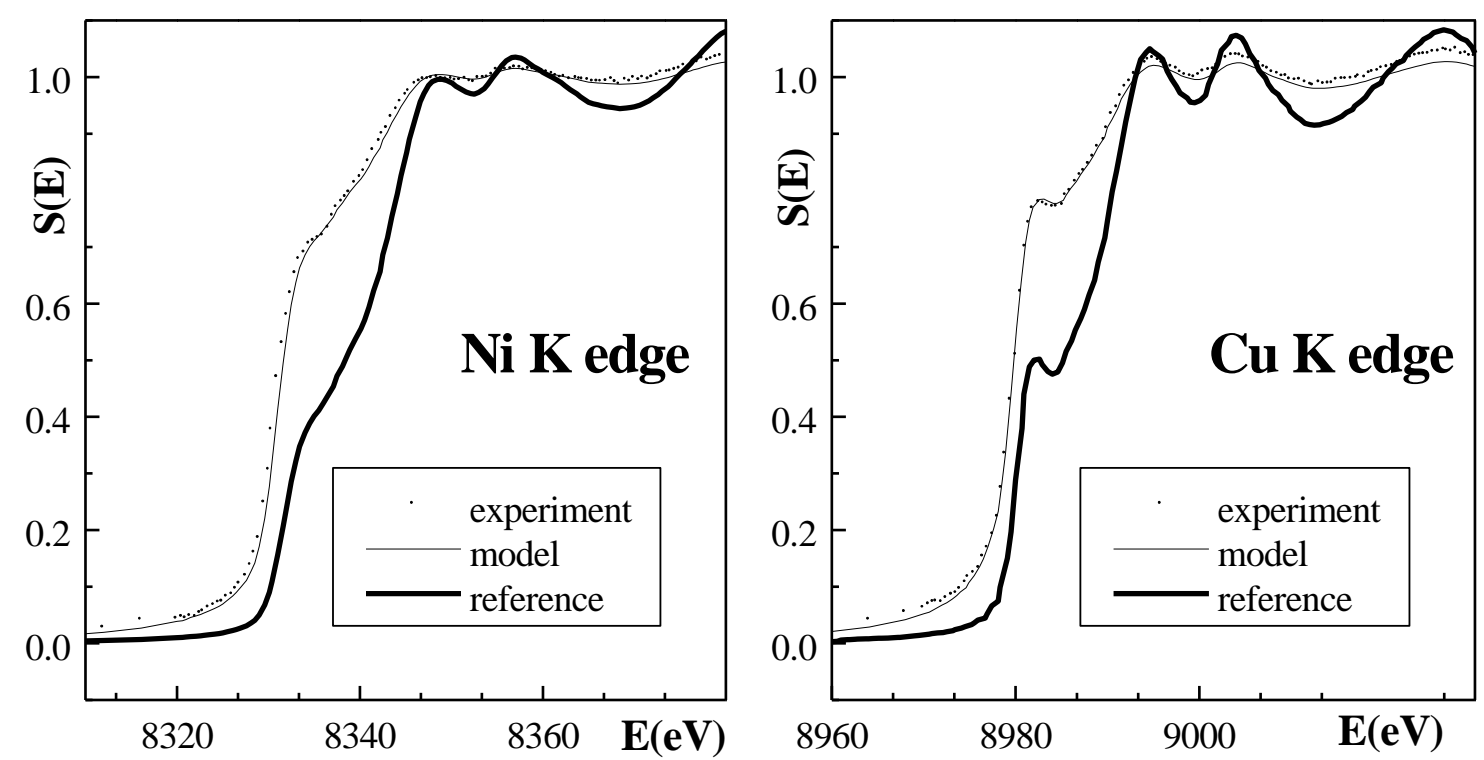

Figure 6. Comparisons of the experimental (points) and calculated (full line) XANES spectra obtained for the 200 $\mathrm{nm}$ thick iron layer deposited on a bulk nickel substrate at the Ni-K edge (a) or on a bulk copper substrate at the $\mathrm{Cu}$ K edge (b).

A logarithmic ratio study was performed on the filtered oscillations of the first coordination shell ${ }^{16}$ in order to quantify the amplitude reduction of the EXAFS signal. Experimental $\mathrm{k} \chi(\mathrm{k})$ EXAFS data were Fourier transformed on the $\left[2.5-12.5 \AA^{-1}\right]$ k-window using a Kaiser form $(\tau=2.5)$. The subsequent filtering was applied on the $[1.7,2.7 \AA]$ range. By this way the amplitude reduction is expressed via two parameters:

- $\mathrm{N}_{\text {fluo }} / \mathrm{N}_{\text {ref }}$, ratio of the near-neighbouring atom number rather specific of a mean value,

- $\Delta \sigma^{2}$, difference of the Debye-Waller term which specifies its k-dependence. 


\begin{tabular}{ccccc}
\hline sample & \multicolumn{2}{c}{$200 \mathrm{~nm} \mathrm{Fe} /$ bulk Ni } & \multicolumn{2}{c}{$200 \mathrm{~nm} \mathrm{Fe} /$ bulk Cu } \\
\hline parameter & $\mathrm{N}_{\text {fluo. }} / \mathrm{N}_{\text {ref. }}$ & $\Delta \sigma^{2}\left(10^{-4} \AA^{2}\right)$ & $\mathrm{N}_{\text {fluo }} / \mathrm{N}_{\text {ref. }}$ & $\Delta \sigma^{2}\left(10^{-4} \AA^{2}\right)$ \\
\hline experiment & 0.24 & -24 & 0.31 & -14 \\
\hline computation & 0.29 & -1.3 & 0.31 & -4 \\
\hline
\end{tabular}

Table 4. First shell relative correlation number $\mathrm{N}_{\text {fluo }} / \mathrm{N}_{\text {ref. }}$ and mean square relative displacement $\Delta \sigma^{2}$ determined from logarithmic ratio analysis of the backscattering amplitudes for the iron recovering bulk sample.

Results are gathered on table 4. Computed spectra are typical of a reduction parameter of $70 \%$ order. Moreover incertitude on the $\sigma^{2}$ value is usually around $10^{-3} \AA^{2}$. The difference $\Delta \sigma^{2}$ is rather negligible considering the error bare. The amplitude reduction can be considered in first approximation as quasi independent of $\mathrm{k}$. Experiments leads to values of the same order. Nevertheless slight differences are observed on both parameters particularly on the $\Delta \sigma^{2}$ values. Such a limited misfit is not very surprising when one considers 1) the smallness of the used experimental electron yield signal and 2) the large energy range where the extrapolation of the pre-edge must be performed to operate the normalisation step. Besides, as shown on Fig. 3.b, the non negligible bulk contribution evidenced on Fig. 2.b certainly alters the result.

\subsection{Amplitude reduction factor of the EXAFS signal for mono-element bulk samples}

The here-proposed model correctly quantifies the amplitude reduction observed for the Fe sublayer on bulk $\mathrm{Ni}$ or $\mathrm{Cu}$ substrate. The extension of such a computation to the analysis of unrecovered bulk samples can be easily performed even if the formalism is a bit different. Absorption of the $\mathrm{K}_{\alpha}$ fluorescent photons leads to the creation of L photoelectrons $(\S 5)$ and no sublayer has to be considered. The same kind of procedure as in the case of bulk Ni sample recovered by a Fe layer (schedule on figure 5 and detailed on $\S 5)$ is followed. After integration over $\zeta$ in the $[0, z]$ range and $z$ in the $[0, \infty[$ one, the expression of the $\mathrm{S}_{\text {fluo }}$ signal generated by a single bulk material can be expressed as:

$$
S_{\text {fluo }}=\frac{I_{0} \times \omega \times \mu_{K}\left(E_{i}\right) \times E_{p h-L} \times D_{p h-L}}{2 \times \cos \beta} \times \mu_{L}\left(E_{K \alpha}\right) \int_{0}^{\pi / 2} F(\theta) \mathrm{d} \theta
$$

with

$$
\mathrm{F}(\theta)=\left[\frac{1}{\mu\left(\mathrm{E}_{\mathrm{i}}\right) / \cos \beta+\mu\left(\mathrm{E}_{\mathrm{K} \alpha}\right) / \cos \theta}-\frac{1}{\mu\left(\mathrm{E}_{\mathrm{i}}\right) / \cos \beta+1 / \mathrm{D}_{\mathrm{ph}-\mathrm{L}}}\right] \times \frac{\sin \theta}{\cos \theta-\mathrm{D}_{\mathrm{ph}-\mathrm{L}} \times \mu\left(\mathrm{E}_{\mathrm{K} \alpha}\right)}
$$

$\mathrm{E}_{\mathrm{ph}-\mathrm{L}}$ and $\mathrm{D}_{\mathrm{ph}-\mathrm{L}}$ are the energy and the sampling depth of the emitted L photoelectrons respectively. $\mathrm{E}_{\mathrm{ph}-\mathrm{L}}$ is in first approximation equal to the mean KLL Auger electron energy :

${ }^{16}$ Lee, P.A., Citrin, P.H., Eisenberger, P. and Kincaid, B.M., 1981, Rev. Mod. Phys., 53, 769 


$$
\mathrm{E}_{\mathrm{ph}-\mathrm{L}}=\mathrm{E}_{\mathrm{K} \alpha}-\overline{\mathrm{E}_{\mathrm{L}}} \approx \mathrm{E}_{\mathrm{K}}-2 \times \overline{\mathrm{E}_{\mathrm{L}}} \approx \overline{\mathrm{E}_{\mathrm{KLL}}}
$$

The $D_{\text {ph-L }}$ values are consequently very close to the $D_{A u}$ ones for a given element (§2.1). Values used for the calculus are these found from equation 3. $S_{\text {fluo }}$ values can be estimated from numerical integration versus the probed element and edge and the incidence angle $\beta$.

As in the $\S 6.2$, experimental transmission reference signals $\left(S_{\text {ref. }}\right)$ of pure materials are used to take into account the EXAFS oscillations of the absorption cross-section $\mu\left(\mathrm{E}_{\mathrm{i}}\right)$ in the $\mathrm{S}_{\text {fluo }}$ calculation. CEY signal $\left(\mathrm{S}_{\mathrm{CEY}}\right)$ having then two contributions - the fluorescence-induced (eq. 6) and the KLL Auger electrons (eq. 4 with KLL Auger electrons as primary electrons) signals - it can be easily numerically estimated:

$$
\mathrm{S}_{\mathrm{CEY}}=\mathrm{S}_{\text {fluo }}+\mathrm{S}_{\infty, \mathrm{KLL}}
$$

Such calculation has been performed for 4 different bulk materials - pure $\mathrm{Ni}, \mathrm{Cu}, \mathrm{Mo}$ and $\mathrm{Ag}$ samples studied at the K-edge for various incidences running from $10^{\circ}$ to $87.5^{\circ}$. In order to take into account the amplitude reduction of the EXAFS signal, we have estimated a k-independent parameter $\Delta \chi / \chi$ defined by:

$$
\Delta \chi / \chi=\frac{\chi_{\mathrm{CEY}}\left(\mathrm{k}_{0}\right)-\chi_{\text {ref. }}\left(\mathrm{k}_{0}\right)}{\chi_{\text {ref. }}\left(\mathrm{k}_{0}\right)}
$$

where $\mathrm{k}_{0}$ is as $\chi\left(\mathrm{k}_{0}\right)$ is maximum. $\chi_{\mathrm{CEY}}(\mathrm{k})$ and $\chi_{\text {ref. }}(\mathrm{k})$ are the EXAFS signal deduced from $\mathrm{S}_{\mathrm{CEY}}$ and $\mathrm{S}_{\text {ref. }}$ respectively. Results of the calculations are plotted on Fig. 7. Two parts can be distinctly observed on the evolution of $\Delta \chi / \chi$ versus $\beta$, for 1) $\beta>80^{\circ}$ and 2) $\beta<80^{\circ}$.

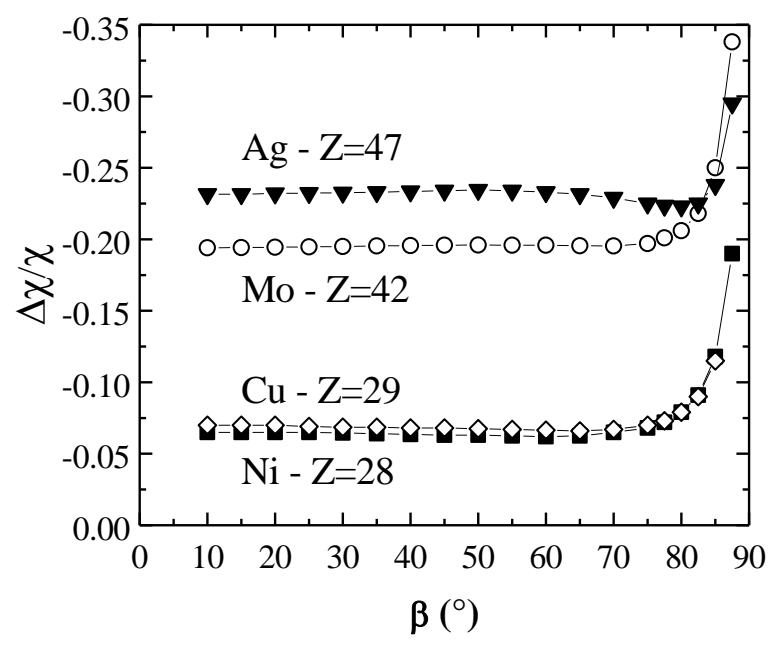

Figure 7. Calculated EXAFS amplitude reduction $\Delta \chi / \chi$ versus the incidence angle $\beta$ for various mono-element bulk samples $\mathrm{K}$ edge studies: $\mathrm{Ni}(\boldsymbol{\square}), \mathrm{Cu}(\diamond), \mathrm{Mo}$ (O), $\operatorname{Ag}(\boldsymbol{\nabla})$.

1) When the beam incidence becomes near the grazing incidence, $\Delta \chi / \chi$ strongly increases. Such deviation is not due to the fluorescent-induced electron yield but to the electron yield itself (eq. 4). This nonlinearity effect has been previously observed ${ }^{5,5}$ (Schrœder 1996b).

2) Considering non grazing incidence the reduction of EXAFS amplitude $\Delta \chi / \chi$ is almost constant for a given element and edge. This evolution might appear contradictory compared with the relative $S_{\text {fluo }}$ signal 
intensity decreasing with the $\beta$ increase (table 1 for the Ag K-edge). But for the resulting amplitude the relative $S_{\text {fluo }}$ intensity decrease is counterbalanced by the increase of the reduction of the linked oscillations amplitude (cf. eq. 5). $\Delta \chi / \chi$ is all the more important since the atomic number of the considered element is high. $\Delta \chi / \chi$ is around $-6.5 \%$ and $-7 \%$, for $\mathrm{Ni}$ and $\mathrm{Cu}$ respectively (low Z-number elements). These reductions are around the error bare often considered for the $\mathrm{N}$ value. Experimental evidence of reduction amplitude around $-5 \% /-10 \%^{2}$ have been previously obtained for Ni K-edge. $\Delta \chi / \chi$ values are higher for high Z-number elements. They are respectively found around $-19.5 \%$ and $-23.5 \%$ for Mo $(Z=42)$ and $\operatorname{Ag}(Z=47)$. Such values agree well with those obtained for $\mathrm{Pd}(Z=46)$ by Schrœder $^{5}$ around $-26 \pm 3 \%$ from experiment and $-22 \%$ from calculation. $\chi(\mathrm{k})$ signals have to be corrected before any simulations of the data for high Z-number K-edge and for bulk samples.

\section{$\S 7$. CONCLUSION}

The experimental results of the present paper agree with an extra electron yield induced by the fluorescent process. This result have been put experimentally in evidence by analysing the CEY signal induced by bulk samples: pure bulk silver (Ag K-edge) and pure bulk nickel or copper recovered by a thin iron layer ( $\mathrm{Ni}$ and $\mathrm{Cu} \mathrm{K}$-edges). Such upper deposited film enhances the effect of the fluorescence beam and strongly reduces the electron emission from the substrate. This fluorescence-electron yield leads to enhance the edge-height, to modify the shape of the XANES and to decrease the EXAFS amplitude.

Extrapolation of the model for mono-element bulk samples was carried out to quantify the EXAFS amplitude reduction due to this phenomenon. Such reduction increases with the atomic number $\mathrm{Z}$ of the studied element. The effects are rather limited for low-Z elements while they become noticeable for high$\mathrm{Z}$ elements. The amplitude reduction can be well-described by a scale factor, its dependence versus the wave vector $\mathrm{k}$ being rather limited in the studied $\mathrm{k}$ range.

This phenomenon is however negligible for experiment performed at the absorption edge of low atomic number element or on samples with a low concentration on the probed element. Samples can then be designed to experimentally avoid the consequences of the fluorescence-induced electron yield. Films deposited on substrate composed of low-Z element of thickness sufficiently inferior to the absorption length of the incident beam do not generate significantly such extra electron yield. Choice of the experimental references, used for the determination of the backscattering amplitude and phase, is crucial when these conditions can not be realised. In order to have a systematic amplitude reduction, the reference have to be as close as possible from the studied samples in a macroscopic point of view. Thickness and composition are then two crucial parameters. In the other cases, this unwanted effect can be corrected performing theoretical calculations adapted to the studied bulk materials (density, energy of the fluorescent $K_{\alpha}$ photons, absorption cross-section at $E_{K \alpha} \ldots$ ) in order to determine with the better accuracy the coordination numbers around the central atom.

\section{ACKNOWLEDGEMENTS}

The authors wish to acknowledge Agnès Traverse for her great assistance and fruitful discussion. 